
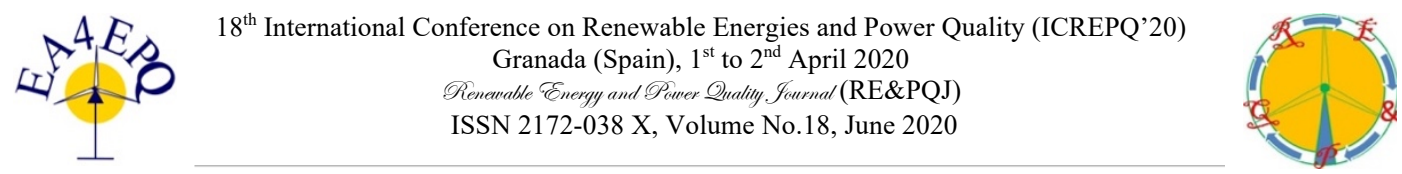

\title{
Cost-optimal configuration of a renewable-based Australian power system
}

\author{
Tino Aboumahboub ${ }^{1, *}$, Robert Brecha ${ }^{1,2}$, Himalaya Bir Shrestha ${ }^{1}$, Ursula Fuentes Hutfilter ${ }^{1}$, \\ Andreas Geiges ${ }^{1}$, William Hare ${ }^{1}$, Michiel Schaeffer ${ }^{3}$, Lara Welder ${ }^{1}$, Matthew Gidden ${ }^{1,4}$ \\ ${ }^{1}$ Climate Analytics \\ Ritterstr. 3, 10969 Berlin (Germany) \\ Phone number: +0049 30259229520, *corresponding author's email: tina.aboumahboub@climateanalytics.org \\ ${ }^{2}$ Physics Department, Renewable and Clean Energy Program, Hanley Sustainability Institute, \\ University of Dayton, Dayton (USA) \\ ${ }^{3}$ The Global Center on Adaptation, Wilhelminakade 149C, 3072 AP Rotterdam, The Netherlands \\ ${ }^{4}$ International Institute for Applied Systems Analysis, Laxenburg (Austria)
}

\begin{abstract}
Proposed emission reduction targets and the scarcity of fossil fuel resources make a transition of the energy system towards an emission-free electricity supply necessary. Australia represents an interesting case for energy system transformation modelling. While it currently has a power system dominated by fossil fuels, and specifically with a heavy coal component, there is a vast potential for expansion and use of renewable energy, in particular solar and wind energy. However, integrating high shares of such variable renewable energy sources challenges the power system due to their temporal fluctuations and geographical dispersion. This paper applies a state-resolved energy system model for Australia, based on linear optimization. We investigate the cost-optimal configuration of a renewable-based Australian power system and its transformation pathway inline with the ambitious proposed climate targets. We particularly analyze the implications of storage and power transmission grid extensions in a prospective, highly renewable Australian power system. Spatial smoothening effects of a powerful transmission grid reduces the required backup and renewable capacities and thus contributes to further reduction of the total system costs.
\end{abstract}

Key words. Power System Optimization, Variable Renewable Energies, Power Transmission, Storage

\section{Introduction}

Australia is characterized by a vast potential of renewable energy sources $[1,2]$. However, the current power system is mainly centralized and still dominated by fossil fuels in most states except the states of South Australia and Tasmania that have already moved toward renewable energy-dominant systems. Around $80 \%$ of total produced power in Australia was generated by coal and gas-fired plants in 2018 [3]. Geographically, the country is divided into seven states and territories, two of which (Western Australia and Northern Territory) have power systems isolated from the rest of the country; New South Wales, Queensland, Victoria, South Australia, and Tasmania are interconnected within the National Electricity Market (NEM) region.

Wind and solar energy could play an important role in the decarbonization of the Australia's future power system. However, integrating high shares of these variable renewable energy sources (VRES) challenges the power system due to their temporal fluctuations and geographical dispersion. Reinforcement of the power transmission grid as well as novel storage systems are necessary to facilitate integrating high shares of VRE.

In order to better understand the further potential expansion of renewable power systems in Australia, we developed the Australian Energy Modelling System (AUSeMOSYS). In this paper we apply the model to investigate the cost-optimal transformation pathways of Australia's electricity system towards a carbon-neutral system. In particular, we analyze the implications of storage and power transmission grid extensions in a prospective, highly renewable Australian power system.

The paper is divided into four parts. In section two the methodology and the model framework is elaborated. Results of the scenario analysis are presented in the third section. Finally, section 4 summarizes the results and draws conclusions.

\section{Model Framework and Analysis Methodology}

To analyze the long-term evolution of Australia's energy system, we developed the Australian Energy Modelling System (AUSeMOSYS) by applying and enhancing the Open Source Energy Modelling System (OSeMOSYS) [4]. The optimization algorithm is based on the concepts of linear programming with an objective function, representing the total system costs. The overall system 
cost minimization is subject to restrictive equations, which describe the energy system, such as the satisfaction of demand, transport and storage losses, conversion losses, technical potential of renewable energies and technical limits of the power plants.

The AUSeMOSYS model incorporates a state-level resolution, consisting of 7 regions: New South Wales (NSW)1, Queensland (QLD), South Australia (SA), Tasmania (TAS), Victoria (VIC), Western Australia (WA), and Northern Territory (NT). The state-level resolution of the model allows to capture regional discrepancies in renewable supply and demand, also representing subnational/state-level energy and climate policies and targets. Optimal power generation capacities, promising sites for installation of renewable technologies as well as interregional transmission capacities result from the optimization process by considering the development of electricity demand over time and further scenario boundary conditions. The current version of the model covers a time horizon until 2050 with annual time steps until 2025 followed by 5-year time steps afterwards. For further information about the mathematical formulation of the model we refer to [4-8].

A brief overview of the general structure of the model is presented in Fig.1. As it is illustrated in the diagram, wind and solar capacity factors and electrical load profiles, rescaled to a consistent spatial resolution, are aggregated to provide data for model regions. In addition, technoeconomic parameters of power generation and storage systems and power transmission lines are feed to the model. Existing infrastructures as well as newly emerging technologies with associated cost reduction and efficiency improvement trends due to learning effects are considered.

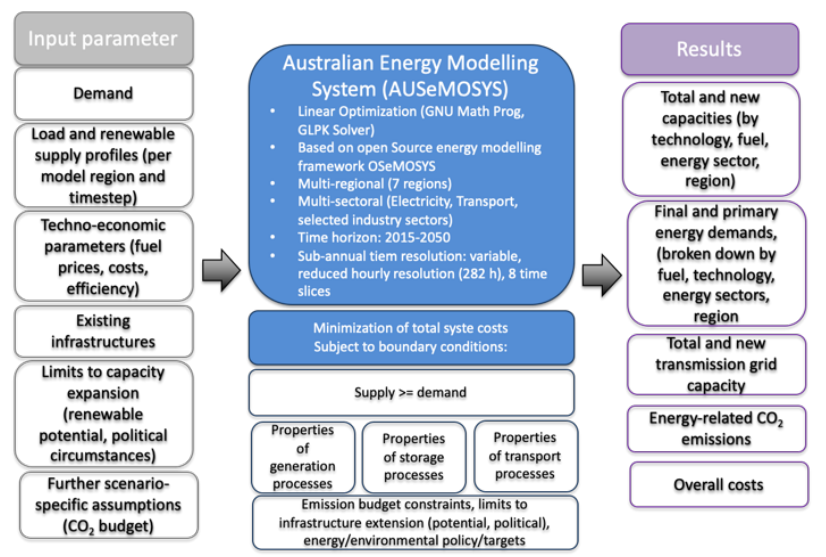

Fig. 1. Model structure

\section{A. Model Database}

As illustrated in Fig. 1, the optimization model is based on various input parameters to represent the load and renewable supply characteristics, existing infrastructures as well as techno-economic characteristics of different power plant technologies, storage systems, and transmission lines, also further scenario-specific constraints and boundary conditions such as $\mathrm{CO}_{2}$ emissions constraint.

\footnotetext{
${ }^{1}$ Australian Capital Territory (ACT) is covered in NSW
}

The Capacity of currently operating power plants has been determined using the UDI World Electric Power Plants Data Base [9] and further extrapolated through future periods by assuming technology-specific lifetimes. Hourly capacity factors of solar PV and wind were calculated based on the data provided by renewables.ninja from the meteorological year $2018 \quad[10,11]$ Electricity transmission is modelled on an aggregated level based on the representative nodes, assuming one node per model region. Maximum capacity of solar PV and wind turbines that can be installed at each model region is restricted to the available geographical potential. This has been derived by taking into account the assessed ranges in various studies, evaluating the technical potential of electricity generation from solar and wind energy in Australia [1,1317]. The electricity demand projections are based on the "Central Scenario" projections as provided in [18], which applies central assumptions about population and economic growth.

Electricity transmission is modelled on an aggregated level based on the representative nodes, assuming one node per model region. A generic transmission technology is assumed with specific investment costs of 306 US\$ per $\mathrm{km}$ and MW (natural power), in line with the ranges assumed in the literature [22,23]. A transmission loss factor of $4 \%$ per $1000 \mathrm{~km}$ is assumed based on [24,25].

\section{B. Model Validation}

The model is based on a number of assumptions, which are typical for modelling purposes. For instance, the maximum production from conventional power plants is restricted by the standard availability factor while contract considerations are not taken into account in dispatch decisions. Moreover, it is assumed that wholesale markets are completely liberalized and the total system costs are minimized through a central planner with perfect foresight. While these deviations from real conditions are typical for modelling purposes, the question, whether the model can properly mimic the behaviour of an actual electricity generation system must be addressed. Question remains concerning the consequent effect of the deviation from an actual condition on the estimation of $\mathrm{CO}_{2}$ emissions. The aim of this part is thus to examine if the applied methodology is capable of representing an actual mix of produced power.

First, we compare the power production mix from the noncalibrated model with the actual power generation data. It is concluded that there exists a general tendency: the model decides to use more coal and lignite than was actually utilized while it underestimates the usage of natural gas- and oil- fired plants. This can be explained on one hand according to the applied deterministic approach, while forecasting errors of electricity load and unforeseen fluctuations of wind power plants are not taken in to account. Moreover, the model respects ramp rates of power plants at a technology level as detailed technical restrictions of power generation units cannot be directly formulated within a non-mixed integer problem. Thus, 
base-and mid-load technologies are considered to be more flexible than real generation plants. As a result, the model uses the cheapest available technology in dispatch decisions, and the contribution of flexible, peak and highpeak generators is underestimated.

A calibrated model is then developed, which yields the least deviation from the real power production mix. One major step in developing a calibrated model is to introduce regionspecific activity constraints for different power plant technologies over historic period 2015-2018. As visualized in Fig. 2, the results in terms of power production technology mix matches well with historic power generation mix as taken from [19,20].

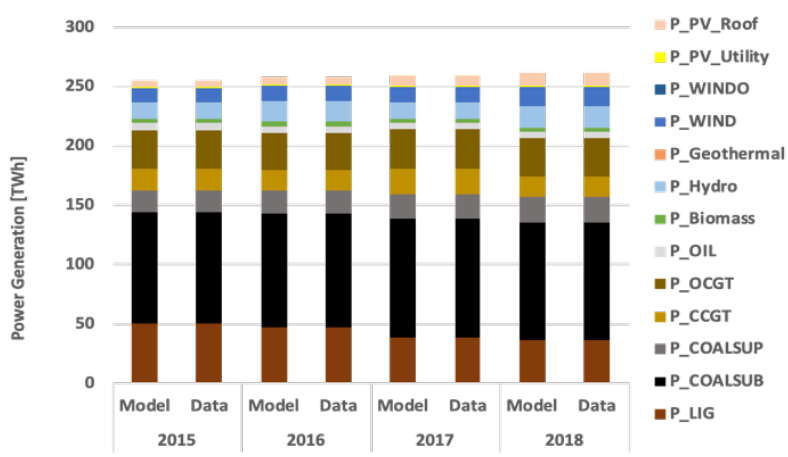

Fig. 2. Calibrated model results versus real electricity generation mix over 2015-2018 (aggregated results for total Australia)

Finally, historic emissions from [21] are used for comparison and validating the model results in terms of $\mathrm{CO}_{2}$ emissions from electricity supply. Total $\mathrm{CO}_{2}$ emissions, obtained from the optimization model are in good accordance with the data. According to the national inventory provided in [21], $\mathrm{CO}_{2}$ emissions from the power sector were 180 million tons in 2019. Applying the calibrated model, total $\mathrm{CO}_{2}$ emissions of year 2019 are estimated at 179 million tons, which shows only $0.3 \%$ deviation. Fig. 3 compares the $\mathrm{CO}_{2}$ emissions from electricity supply over 2015-2019 between the model results and historic data, which proves a good match.

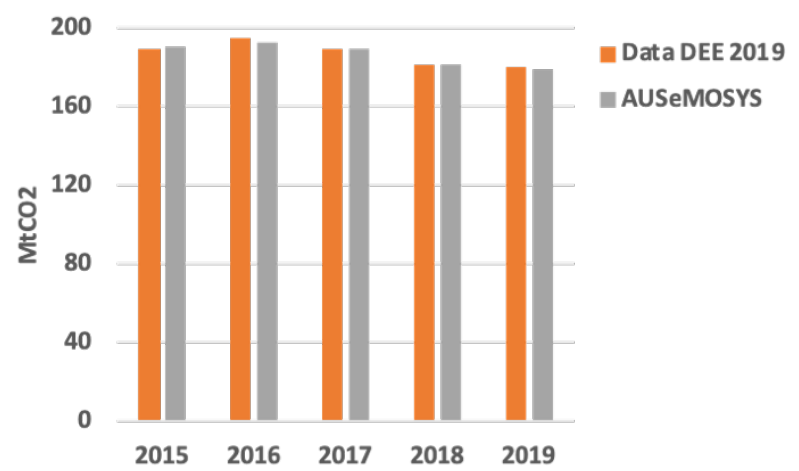

Fig. 3. Model results in terms of total $\mathrm{CO}_{2}$ emissions from Australia's electricity supply over 2015-2019 versus historic emissions

\section{Scenario Analysis}

\section{A. Scenario framework}

Several boundary conditions such as transmission capacity constraints and available storage options as well as implied climate policies and mitigation targets have significant impacts on the optimal configuration of the future energy system and the feasible share of VRES. Through scenariobased analysis and combination of mentioned boundary conditions, sensitivity of the model results to different key factors is investigated.

Here, we consider an "Enhanced Renewables" scenario (EnhRE), where the renewable energy transition dominates the transformation pathway of Australia's energy system. In this scenario, renewable technologies achieve market competitiveness at a high pace, which is mainly driven by the implied $\mathrm{CO}_{2}$ emissions constraint; in addition, this scenario incorporates ambitious assumptions about cost decline of renewable-based technologies and energy efficiency improvements. The results obtained from the "Enh RE" scenario is compared against a Reference Scenario. The latter has no assigned $\mathrm{CO}_{2}$ budget and is characterized by the dominance of fossil fuel-based, emission-intensive technologies similar as today.

In addition, to analyze the implications of key influencing factors, we include different sensitivity cases by varying the transmission capacity growth constraints and storage costs. Table I represents the scenario framework applied in this study.

Table I. - Scenarios and underlying assumptions

\begin{tabular}{|c|c|}
\hline Scenario & Underlying Assumptions \\
\hline Reference & 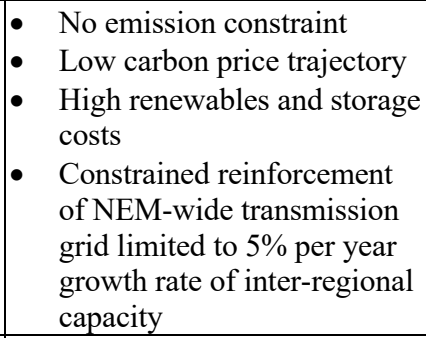 \\
\hline $\begin{array}{l}\text { Enhanced Renewables } \\
\text { (EnhRE) }\end{array}$ & $\begin{array}{l}1.5^{\circ} \mathrm{C} \text { compatible budget of } \\
3.1 \mathrm{GtCO}_{2} \text { over 2018-2050 } \\
\text { High cost reduction and } \\
\text { efficiency improvement } \\
\text { assumed for renewable } \\
\text { technologies and storage } \\
\text { Only NEM interconnected } \\
\text { with inter-regional capacity } \\
\text { growth constraint of } 10 \% \\
\text { per year (WA and NT act as } \\
\text { isolated regions) }\end{array}$ \\
\hline EnhRE-LinkAUS & $\begin{array}{l}\text { Whole supply area is } \\
\text { interconnected, linking WA } \\
\text { and NT to the NEM region } \\
\text { possible }\end{array}$ \\
\hline $\begin{array}{l}\text { EnhRE-PVSto-CostH } \\
\text { (EnhRE-StoCH) }\end{array}$ & $\begin{array}{l}\text { Higher costs assumed for } \\
\text { solar PV and battery storage } \\
\text { systems than EnhRE }\end{array}$ \\
\hline
\end{tabular}

\section{B. Model Results}

Fig. 4 and Fig. 5 visualise the development of power production mix over time for different scenarios. Total renewables share reaches to $95 \%$ in 2030 and full 
renewable supply is achieved by 2035 in the "EnhRE" scenario. The renewable power production is dominated by VRES, where solar and wind power accounting for around $94 \%$ of total generation in 2050 . For comparison, the power production mix under the Reference scenario is mainly centralised and fossil fuel based as today. In addition, to achieve the ambitious $\mathrm{CO}_{2}$ mitigation targets in the most cost-efficient manner there is a need for strong sectorcoupling, which allows to increase the feasible integration share of renewables across all energy sectors beyond the power sector only. Hence, total electricity demand reaches to 1.7 times of today by 2050 under the "EnhRE" scenario due to additional electricity demand required for electrification of end-use sectors under stringent $\mathrm{CO}_{2}$ budget.

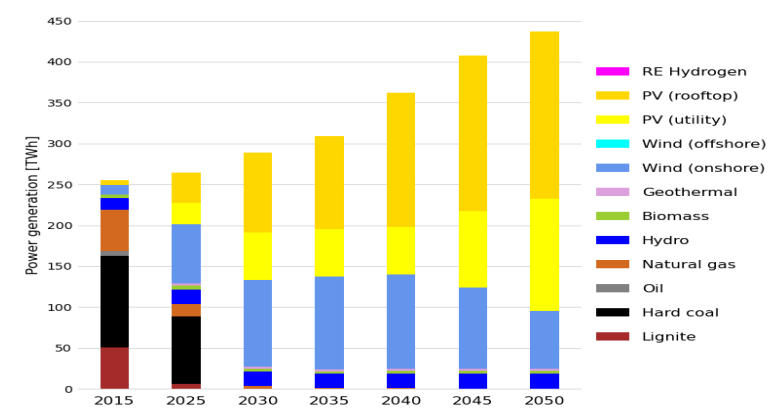

Fig. 4. Power production mix over time for "EnhRE" scenario (aggregated results for total Australia)

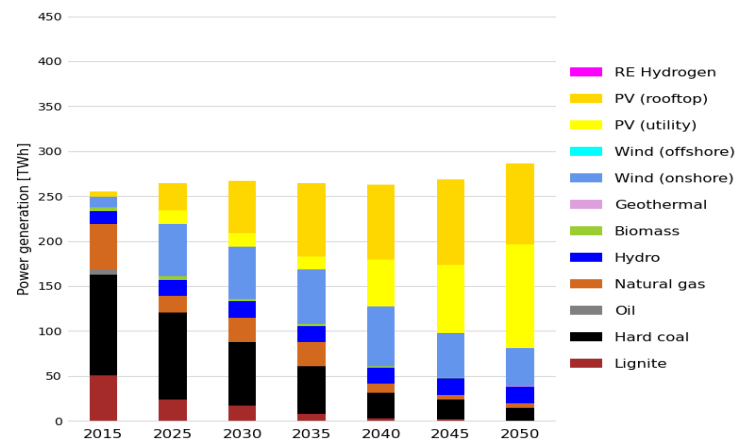

Fig. 5. Power production mix over time for Reference scenario

Fig. 6 visualizes the power generation capacity over time for the "EnhRE" scenario. Total power plants capacity increases to $230 \mathrm{GW}$ in 2050 , from which $220 \mathrm{GW}$ comes from VRE generation capacity, i.e. solar PV and wind. The storage capacity, dominated by battery storage systems to buffer temporal mismatches between solar PV generation and load, increases to around $47 \mathrm{GW}$ in 2050. A highly renewable power supply system benefits from a powerful area-wide transmission grid. The transmission grid is then mainly applied to smoothen the variability of wind power generation in spatial dimension and reduces the required backup and VRE generation capacity. Hence, when the whole supply area is interconnected in the "EnhRELinkAUS" scenario, total required backup capacity reduces by $7 \%$ as compared to the "EnhRE" scenario. The required VRE generation capacity also reduces by $4 \%$ in the EnhRELinkAUS scenario as compared to the scenario "EnhRE".

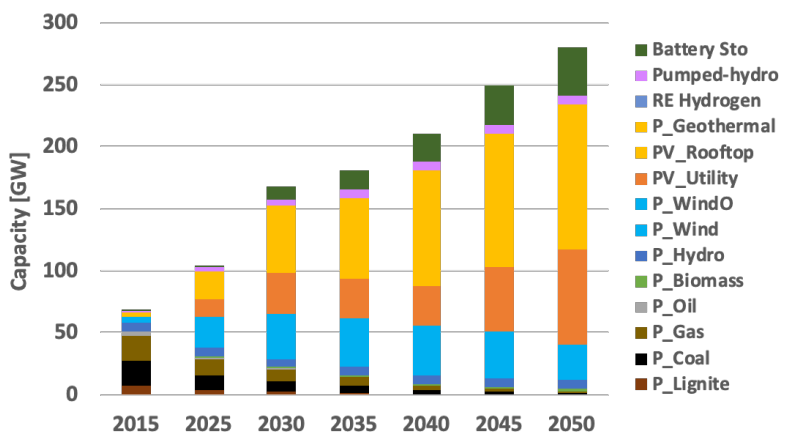

Fig. 6. Power plants and storage capacity over time for EnhRE scenario

Fig. 7 visualizes the cost-optimal inter-regional power transmission capacities obtained from the scenario "EnhRE-LinkAUS". This leads to more than doubling the total inter-regional transmission capacity by 2030 and more than 6 times of today's capacity in 2050 .
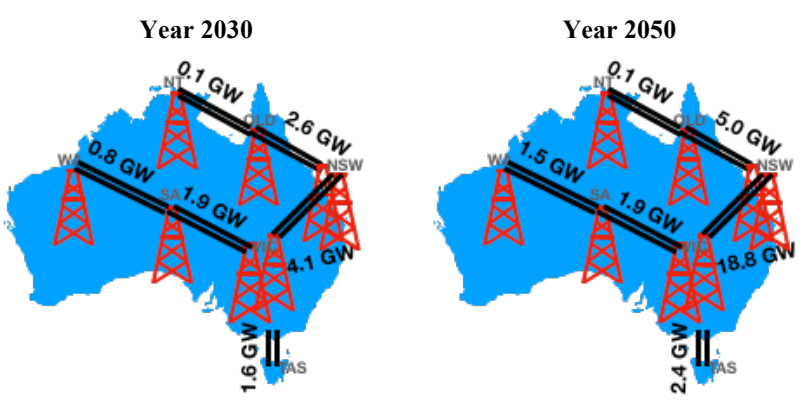

Fig. 7. Cost-optimal power transmission capacities in scenario "EnhRE-LinkAUS"

Fig. 8 shows the optimal geographic distribution of power production mix in scenario "EnhRE-LinkAUS". A powerful, Australia-wide transmission grid allows for an ideal geographic distribution of solar and wind power plants. The transmission grid and storage are then mainly applied to buffer the mismatches between VRE supply and demand in temporal and spatial dimension.
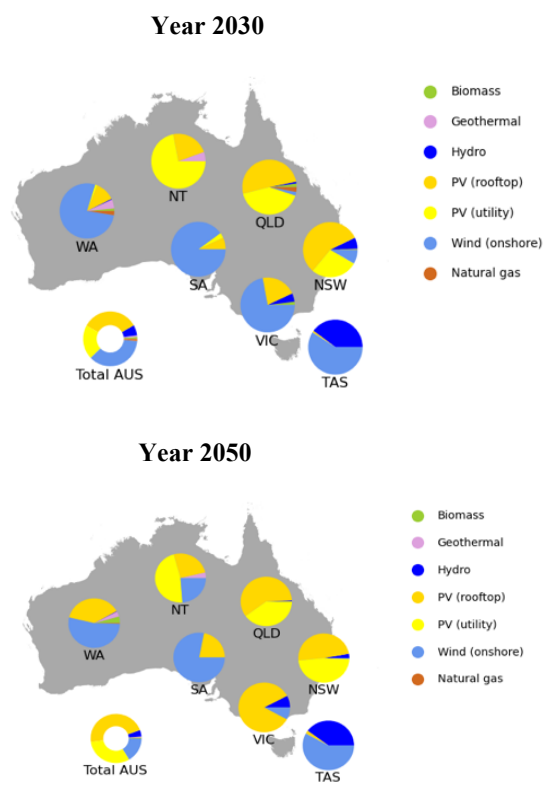

Fig. 8. Regional distribution of power production mix in scenario "EnhRE-LinkAUS" 
The analysed scenarios so far incorporate ambitious cost declines for solar PV and battery storage systems. Therefore, we investigate the implications of higher cost assumptions for solar PV and storage systems in scenario "EnhRE-StoCH". In scenario "EnhRE-StoCH", the share of solar PV in total produced electricity reduces to $27 \%$ by 2030 (54\% in the "EnhRE" scenario), while wind share increases to $63 \%$ (37\% in the "EnhRE" scenario). In 2050, share of solar PV reaches to $50 \%$, whereas wind power accounts for $45 \%$ of total power production; corresponding VRE shares in the "EnhRE" scenario are: 78\% solar PV and $16 \%$ wind power. Finally, Fig. 9 shows the regional distribution as well as total Australia's power production fuel mix in the "EnhRE-StoCH" scenario for different years.
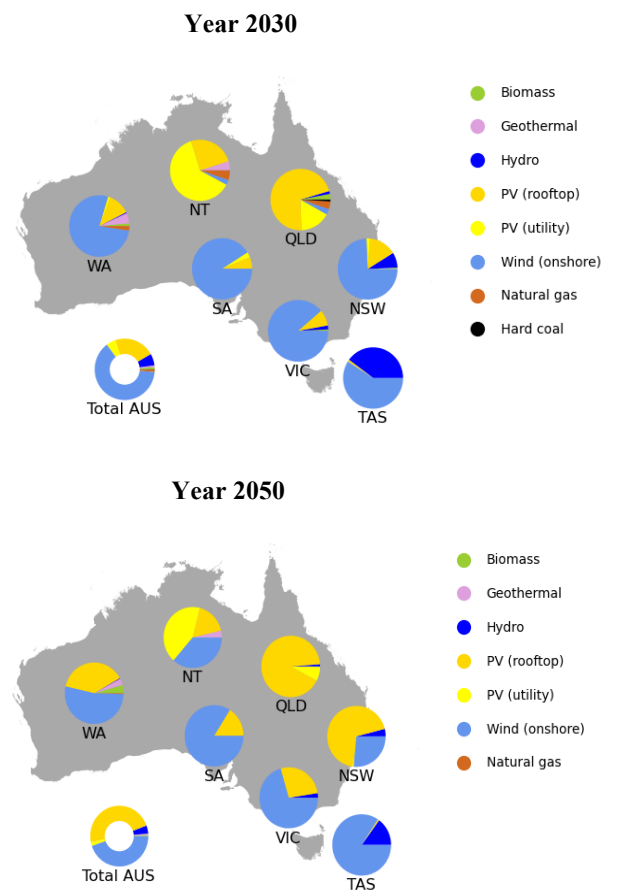

Fig. 9. Power production mix in scenario "EnhRE-StoCH" for years 2030 and 2050 .

\section{Conclusion}

In this study, a multi-regional, state-resolved energy system model for the analysis of long-term evolution of the Australian energy system has been developed. The modelling approach, presented here, allows for representing the cost-optimal power generation capacities, optimal geographic distribution of VRE generation plants as well as inter-regional transmission and required storage capacities under given scenario-specific boundary conditions such as $\mathrm{CO}_{2}$ budget constraints.

The optimal structure of a $\mathrm{CO}_{2}$-constrained power supply system has been studied through scenario analysis. An ambitious mitigation scenario with high shares of variable renewable energies in line with the Paris Agreement Climate target has been compared against a Reference scenario with low mitigation effort. In addition, sensitivity of the results to the Photovoltaic and storage systems associated costs have been investigated. According to the scenario results, to achieve the ambitious proposed climate targets, there is a need for substantial decline of fossil-fuel based generation, in particular phase out of coal-fired plants by 2030; full renewable supply is achieved by 2040 . To facilitate integrating such high shares of VRES, there is a need for reinforcement of transmission grid as well as extension of storage capacities. Through a powerful Australia-wide power transmission grid, required backup power and storage capacities decline and ambitious mitigation targets can be achieved in the most costefficient manner. This can be realized as it provides the infrastructure to achieve smoothening effects of dispersed generation. It makes the most promising sites for renewable electricity production accessible for wide-area usage and powerfully integrates the dispatchable fossil fuel technology for instant load following purposes and backup applications. Therefore, the overall installed capacity and excess production share reduce compared to the isolated power supply systems with exclusion of longdistance transport possibility.

From a macro-economic perspective, minimization of overall system costs, which corresponds to maximization of producers' and consumers' surplus, defines an ideal operation of the energy system through a central planner. The AUSeMOSYS model is solved through intertemporal optimization over a long-term horizon, assuming perfect foresight. The model results should thus not be interpreted as predictive nor directive. Such bottom up modelling approach applied in this study rather provides a robust analytical basis to analyze systematic effects and interactions between various contributing elements of energy system. It additionally provides valuable insights on possible least-cost decarbonization pathways of the Australia's energy system in line with the proposed ambitious climate targets.

\section{Acknowledgement}

Authors want to express special thanks to Konstantin Loeffler for the interesting discussions and feedbacks through the process of model development.

\section{References}

[1] Teske S, Giurco D, Morris T, Nagrath K, Mey F, Briggs C, et al. Achieving the Paris Climate Agreement Goals. Springer; 2019.

[2] Teske S, Dominish E, Ison N, Maras K. 100\% Renewable Energy for Australia - Decarbonising Australia's Energy Sector within one Generation 2016.

[3] DEE. Australian Energy Statistics, Table O, Australian electricity generation by fuel type n.d.

[4] Howells M, Rogner H, Strachan N, Heaps C, Huntington H, Kypreos S, et al. OSeMOSYS: The Open Source Energy Modeling System. An introduction to its ethos, structure and development. Energy Policy 2011;39:5850-70.

https://doi.org/10.1016/j.enpol.2011.06.033.

[5] Burandt T, Löffler K HK. GENeSYS-MOD v2.0 Enhancing the Global Energy System Model: Model Improvements, Framework Changes, and European Data Set, DIW Data Documentation 94. DIW, Berlin: 
2018.

[6] Löffler K, Hainsch K, Burandt T, Oei PY, Kemfert C, Von Hirschhausen C. Designing a model for the global energy system-GENeSYS-MOD: An application of the Open-Source Energy Modeling System (OSeMOSYS). Energies 2017;10. https://doi.org/10.3390/en10101468.

[7] Burandt T, Xiong B, Löffler K, Oei PY. Decarbonizing China's energy system - Modeling the transformation of the electricity, transportation, heat, and industrial sectors. Appl Energy 2019;255:113820. https://doi.org/10.1016/j.apenergy.2019.113820.

[8] Aboumahboub T, Brecha R, Gidden M, Geiges A, Shrestha HB. Integrating energy sectors in a stateresolved energy system model for Australia. Spat. temporal Model. Renew. energy Syst. EGU 2020 Gen. Assem., European Geosciences Union; 2020. https://doi.org/https://doi.org/10.5194/egusphereegu2020-20428.

[9] Platts UDI Products Group. Data Base Description and Research Methodology: UDI World Electric Power Plant Data Base (WEPP). Platts, a Division of The McGraw-Hill Companies, Washington DC: 2019.

[10] Pfenninger S, Staffell I. Long-term patterns of European PV output using 30 years of validated hourly reanalysis and satellite data. Energy 2016;114:1251-65. https://doi.org/10.1016/j.energy.2016.08.060.

[11] Staffell I, Pfenninger S. Using bias-corrected reanalysis to simulate current and future wind power output. Energy 2016;114:1224-39. https://doi.org/10.1016/j.energy.2016.08.068.

[12] AEMO. Interconnector capabilities for the National Electricity Market. 2017.

[13] Teske S, Dominish E, Ison N, Maras K. 100\% Renewable Energy for Australia: Decarbonising Australia's Energy Sector Within One Generation. Sydney: 2016.

[14] Eurek K, Sullivan P, Gleason M, Hettinger D, Heimiller D, Lopez A. An improved global wind resource estimate for integrated assessment models. Energy Econ 2017;64:552-67.

https://doi.org/10.1016/j.eneco.2016.11.015.

[15] Clarke DK. Wind power potential and consumption, by state 2020.

https://ramblingsdc.net/Australia/WindPPotential.html\# Potential_wind_power_in_Australia_by_state_graph (accessed April 6, 2020).

[16] Bureau of Meteorology GA. Australian Energy Resource Assessment - Chapter 10 Solar Energy. 2009.

[17] Roberts M, Nagrath K, Briggs C, Copper J, Bruce A, McKibben J. How much rooftop solar can be installed in Australia? 2019.

[18] AEMO. Draft 2020 Integrated System Plan For the National Electricity Market. 2019.

[19] Connell, D., Court, S. H. à., \& Tan S. An Open Platform for National Electricity Market Data. 2020 n.d. https://opennem.org.au/energy/nem.

[20] DEE. Australian Energy Statistics, Table O Australian electricity generation, by fuel type, physical units. 2019 .

[21] DEE. Australia's emissions projections 2019, Commonwealth of Australia 2019. 2019.

[22] Blakers A, Lu B, Stocks M. 100\% renewable electricity in Australia. Energy 2017;133:471-82. https://doi.org/10.1016/j.energy.2017.05.168.

[23] Schaber K. Integration of Variable Renewable Energies in the European power system: a model-based analysis of transmission grid extensions and energy sector coupling. Ntegration Var Renew Energies Eur Power Syst a Model Anal Transm Grid Extensions Energy Sect Coupling 2013:199.

[24] Jeppesen M, Brear MJ, Chattopadhyay D, Manzie C,
Dargaville R, Alpcan T. Least cost, utility scale abatement from Australia's NEM (National Electricity Market). Part 1: Problem formulation and modelling. Energy 2016;101:606-20.

https://doi.org/http://dx.doi.org/10.1016/j.energy.2016. 02.017 .

[25] IEA ETSAP. Electricity transmission and distribution. 2014. 